\title{
Prevalence and determinants of chronic obstructive pulmonary disease among a sample of adult smokers in Baghdad, Iraq, 2014
}

Faris Al Lami ${ }^{1}$ and Zainab Salim ${ }^{2}$

\begin{tabular}{|c|}
\hline 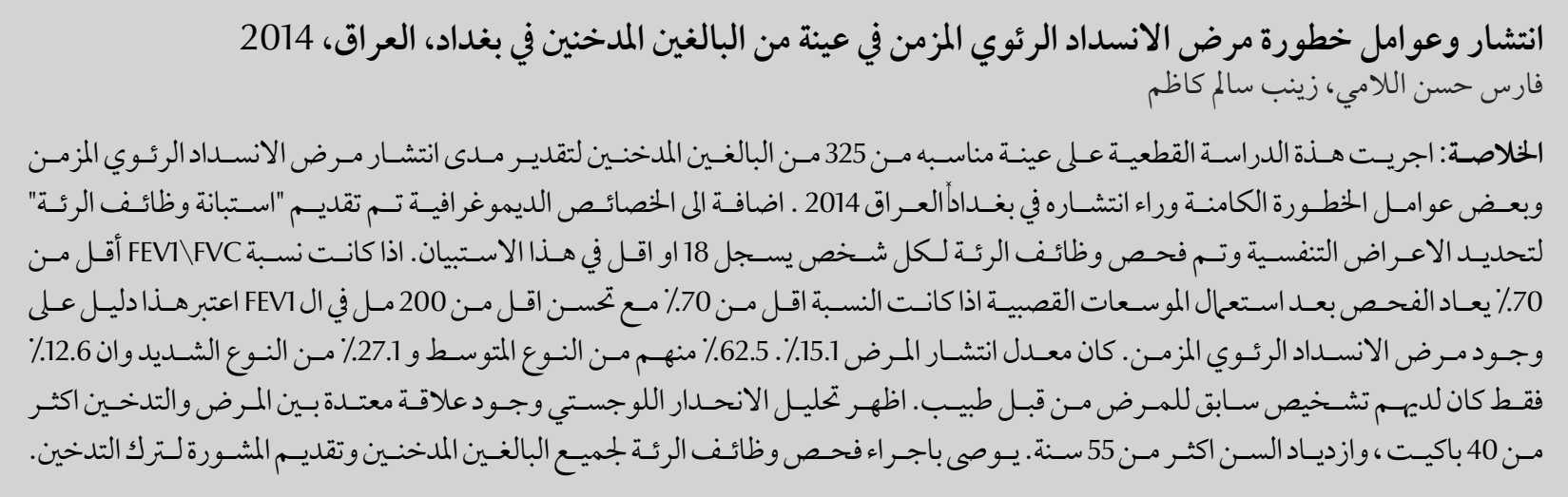 \\
\hline
\end{tabular}

ABSTRACT This cross-sectional study was conducted to estimate the prevalence and identify determinants of chronic obstructive pulmonary disease (COPD) among a convenience sample of 325 adult smokers in Baghdad, Iraq, 2014. Beside demographic variables, participants had Lung Function Questionnaire to assess respiratory symptoms; individuals with a score of $\leq 18$ had a spirometry examination. Those with FEV1/FVC ratio $<70 \%$ had post bronchodilator spirometry; those with FEV1/FVC\% of $<70 \%$ and $<200 \mathrm{ml}$ improvement of FEV1 were considered COPD cases. Staging of COPD is done according to the degree of FEV1 reduction. The prevalence of COPD was $15.1 \%$ (95\% confidence interval $11.5-19.4 \%$ ); $62.5 \%$ had moderate and $27.1 \%$ had severe COPD. Only $12.5 \%$ had a prior physician diagnosis. Age $>55(\mathrm{OR}=2.14,95 \%$ confidence interval $=1.04-4.39)$, and pack year smoking $>40(\mathrm{OR}=5.37,95 \%$ confidence interval $=1.70-16.91)$ were the significant independent determinants. All adult smokers should have a spirometry testing and counseled to stop smoking.

\section{Prévalence et déterminants de la bronchopneumopathie chronique obstructive dans un échantillon de fumeurs adultes à Bagdad (Iraq) en 2014}

RÉSUMÉ La présente étude transversale a été conduite dans le but d'estimer la prévalence de la bronchopneumopathie chronique obstructive (BPCO) et d'identifier ses déterminants dans un échantillon de commodité de 325 fumeurs adultes à Bagdad (Iraq) en 2014. En plus des variables démographiques, les participants devaient remplir un questionnaire sur les fonctions pulmonaires afin d'évaluer les symptômes respiratoires. Les individus ayant obtenu un score inférieur ou égal à 18 devaient se soumettre à un test de spirométrie. Ceux qui présentaient un rapport VEMS/CVF (volume maximal expiré pendant la première seconde d'une expiration forcée/capacité vitale forcée) inférieur à $70 \%$ avaient une spirométrie post-bronchodilatateur ; ceux avec un rapport VEMS/CVF de moins de $70 \%$ et une amélioration du VEMS inférieure à $200 \mathrm{ml}$ étaient considérés comme des cas de BPCO. Les stades de la BPCO sont déterminés en fonction du degré de diminution du VEMS. La prévalence de la BPCO était de 15,1 \% (intervalle de confiance à $95 \%=11,5-19,4 \%$ ), $62,5 \%$ souffraient de BPCO modérée et 27,1 \% d'une BPCO sévère. Un diagnostic médical avait été posé au préalable pour seulement 12,5\% des participants. Un âge supérieur à 55 ans $(O R=2,14$, intervalle de confiance à $95 \%=1,04-$ 4,39), et une consommation de paquets-année supérieure à $40(\mathrm{OR}=5,37$, intervalle de confiance à $95 \%=1,70$ $16,91)$ était les déterminants indépendants significatifs. Tous les fumeurs adultes devraient bénéficier d'un test de spirométrie et de conseils pour arrêter de fumer.

'Department of Community Medicine, College of Medicine, Baghdad University, Baghdad, Iraq (correspondence to: F. Al Lami:farislami@gmail. com). ${ }^{2}$ Ministry of Health, Baghdad, Iraq.

Received: 19/04/15; accepted: 10/05/16 


\section{Introduction}

Chronic obstructive pulmonary disease (COPD) is an important and growing cause of morbidity and mortality worldwide (1-3). The WHO Global Burden of Disease Project estimated that COPD was the fifth leading cause of death worldwide in 2001 and will be the third leading cause by 2020 (1). It is a preventable and treatable disease characterized by airflow limitation that is not fully reversible (3).

In the early stages, COPD can be symptomless; later long episodes of coughing, often with sputum production, develops. In the later stages, when a large portion of the lung capacity may already have been lost, symptoms of dyspnoea on exertion will develop. Usually COPD is diagnosed in the later stages, and this diagnostic delay may either be due to the patient's gradual adaptation to a decreasing lung function or because doctors are unaware of, or not responding to, the symptoms (4).

The major risk factor for COPD is cigarette smoking (5), other irritants such as domestic fuel, air pollution and chemical fumes or dust from the environment or workplace can also contribute. Older age and male sex are also associated with COPD (6). Spirometry is needed to make a confident diagnosis of irreversible airway obstruction: (post-bronchodilator FEV1/FVC $<0.7$ according to GOLD guidelines (3).

Although around $90 \%$ of deaths due to COPD occur in low- or middleincome countries, very few data on the prevalence of this illness are available in these countries (7). In one large study done in the Middle East and North Africa, which included a large sample of individuals aged $>40$ years in 10 countries, the overall prevalence of COPD was $3.6 \%$ (8). Prevalence increases considerably with age and intensity of smoking, and can vary from $25 \%$ in a general smoking population to approximately $50 \%$ in an elderly smoking population (9-11).

The objective of the current study was to estimate the prevalence of COPD among a sample of adult smokers in Baghdad and to identify certain determinants underlying its development.

\section{Methods}

\section{Sample}

A cross-sectional study was conducted in 3 primary health care centres in Baghdad, Iraq, during the period 1 May-30 October 2014. There are 118 PHCCs in Al Karekh Directorate of Health (western Baghdad) and 116 in Al Rusafa (eastern Baghdad). After discussion with the officials at the 2 directorates of health, we made a convenience selection of 3 centres where we had determined that the catchment populations included different socioeconomic classes.

The sample size was calculated using the formula $n=z^{2} p q / d^{2}$

$$
\begin{gathered}
n=(1.96)^{2} \times 0.15 \times 0.85 /(0.04)^{2} \\
n=318
\end{gathered}
$$

We selected 325 individuals to be included in our study. We invited all current or former cigarette smokers aged $\geq 35$ years attending these 3 primary health care centres for any reason other than respiratory problems and who fulfilled the inclusion criteria to participate in the study until we achieved the required sample size. There were no refusals to participate. Pregnant women and those with contraindications to bronchodilators were excluded.

Previously, a pilot study was done on 10 smokers aged $\geq 35$ years in one of the selected primary health care centres to assess the validity of the questionnaire and the time needed to complete the questionnaires and having the spirometry test. No changes were made to the questionnaire and the time allocated to complete the tests was adequate.

\section{Data collection}

Two questionnaires were used and completed by the investigator through direct interviews with the study participants. The first included questions on sociodemographic data: age, sex, residence, occupation, education, and income. Smoking history was documented as current or former smoker besides the number of cigarettes smoked per day and years of smoking. Pack years smoking was calculated by multiplying number of cigarette smoked per day by years of smoking divided by 20 (no. of cigarettes per pack) (2). This was categorized into 3 groups: $1-20,21-40$ and $>40$.

History of comorbid chronic diseases, including hypertension, diabetes and liver or renal diseases, and any previous diagnosis of chronic bronchitis, emphysema or COPD was recorded.

The second questionnaire was the Lung Function Questionnaire, which comprises 5 questions scored on a 5-point Likert scale (very often $=$ every day, often $=$ most days of the week, sometimes $=1-2$ times per week, rarely $=<1$ time per week, never $=0$ times per week), with lower scores indicating increased risk of airflow obstruction (12). The questionnaire was administered via face-to-face interview by one of the researchers (ZS). The first 3 questions asked about how often the patients experienced coughing up mucus, wheezing and shortness of breath during physical activity. A total score of $\leq 18$ suggests an increased risk of airway obstruction (12): all individuals with a score of $\leq 18$ on the questionnaire were given a pulmonary function test using the spirometer.

\section{Spirometry}

Spirometry was performed according to the recommendations of the American Thoracic Society (13). We used the Discovery 2 portable spirometer (Futuremed). Every patient who had FEV1/FVC $<70 \%$ then underwent 
post-bronchodilator spirometry, using 2 puffs 1 minute apart of inhaled Ventolin, and after 30 minutes spirometry was repeated; FEV1/FVC \% $<70 \%$ and $<200 \mathrm{~mL}$ improvement of FEV1 is considered irreversible obstruction (COPD). Staging of COPD was then done according to the GOLD classification (3): mild FEV1/FVC $<0.7$ FEV1 $\geq 80 \%$ of predicted, moderate FEV $1<0.7$ FEV $1 \geq 50-<80 \%$ of predicted, severe FEV $\backslash \backslash F V C<0.7$ FEV 1 $\geq 30-<50 \%$ of predicted and very severe FEV $1 \backslash F V C<0.7 \mathrm{FEV} 1<30 \%$ of predicted.

\section{Statistical analysis}

We used SPSS, version 20, for data entry and analysis. The chi-squared test of independence was used to test the association between variables. Logistic regression analysis was applied with the presence of COPD as the outcome variable and the demographic and smoking characteristics as independent variables. Odds ratio (OR) and its 95\% confidence interval $(\mathrm{CI})$ were calculated; $P$ value $<0.05$ was considered statistically significant.

\section{Ethical approval}

Ethical approval was obtained from the health research committee in the Iraqi Ministry of Health and the Iraqi Board of Medical Specializations. All participants were informed about the study and verbal approval was obtained before enrolment.

\section{Results}

From the total sample of 325 smokers and ex-smokers of both sexes, 273 (84\%) were males. The mean age was 51.1 [standard deviation (SD) 10.8] years. All were urban residents. Further demographic characteristics are detailed in Table 1.

Chronic disease was present in $46.5 \%$ of the participants, hypertension in $37.8 \%$, diabetes in $18.8 \%$ and ischaemic heart diseases in $6.5 \%$. The study sample included current smokers (85.8\%) and ex-smokers (14.2\%). Mean pack years smoking was 40.7 (SD 30.2).

We found that 282 (86.8\%) participants scored $\leq 18$ on the Lung

\begin{tabular}{|c|c|c|c|c|c|c|}
\hline \multirow[t]{2}{*}{ Sociodemographic characteristics } & \multicolumn{2}{|c|}{ With COPD $(n=48)$} & \multicolumn{2}{|c|}{ Without COPD $(n=270)$} & \multirow[t]{2}{*}{$\chi^{2}$} & \multirow[t]{2}{*}{$P$-value } \\
\hline & No. & $\%$ & No. & $\%$ & & \\
\hline \multicolumn{7}{|l|}{ Age (years) } \\
\hline $35-44$ & 2 & 2.0 & 100 & 98.0 & \multirow{4}{*}{25.5} & \multirow{4}{*}{$<0.01$} \\
\hline $45-54$ & 17 & 16.8 & 84 & 83.2 & & \\
\hline $55-64$ & 14 & 20.9 & 53 & 79.1 & & \\
\hline$\geq 65$ & 15 & 31.2 & 33 & 68.8 & & \\
\hline \multicolumn{7}{|l|}{ Sex } \\
\hline Male & 40 & 15.0 & 227 & 85.0 & \multirow{2}{*}{0.017} & \multirow{2}{*}{0.897} \\
\hline Female & 8 & 15.7 & 43 & 84.3 & & \\
\hline \multicolumn{7}{|l|}{ Education } \\
\hline Illiterate/primary & 11 & 23.9 & 35 & 76.1 & \multirow{3}{*}{4.01} & \multirow{3}{*}{0.134} \\
\hline Secondary & 19 & 15.7 & 102 & 84.3 & & \\
\hline Higher & 18 & 11.9 & 133 & 88.1 & & \\
\hline \multicolumn{7}{|l|}{ Occupation } \\
\hline Unemployed & 19 & 44.2 & 24 & 55.8 & \multirow{3}{*}{32.99} & \multirow{3}{*}{$<0.001$} \\
\hline Employed & 25 & 10.7 & 219 & 89.3 & & \\
\hline Homemaker & 4 & 12.9 & 27 & 87.1 & & \\
\hline \multicolumn{7}{|l|}{ Income $^{a}$} \\
\hline Low & 22 & 21.6 & 80 & 78.4 & \multirow{3}{*}{4.94} & \multirow{3}{*}{0.084} \\
\hline Middle & 21 & 12.3 & 150 & 87.7 & & \\
\hline High & 5 & 11.1 & 40 & 88.9 & & \\
\hline \multicolumn{7}{|l|}{ Crowding index } \\
\hline$>2$ & 29 & 19.5 & 120 & 80.5 & \multirow{2}{*}{4.17} & \multirow{2}{*}{0.041} \\
\hline$\leq 2$ & 19 & 11.2 & 150 & 88.8 & & \\
\hline
\end{tabular}

${ }^{a}$ Low income > 500000 Iraqi Dinars; middle income 500 000-1300 0000 Iraqi Dinars; high income > 1300000 Iraqi Dinars. 
Function Questionnaire, i.e. were at risk of COPD (Figure 1). All were given the pulmonary function (spirometry) test; this was obstructive in 59 (20.9\%) participants. Those who showed an obstructive pattern had post-bronchodilator spirometry and in $48(81.3 \%)$ the obstruction was irreversible, i.e. COPD. The remaining 11 (18.7\%) showed reversible obstruction (asthma) (Figure 1).

The prevalence of COPD among the study sample was $15.1 \%$ (95\% CI: 11.5-19.4\%): $10.4 \%$ had mild (stage I), $62.5 \%$ had moderate (stage II) and $27.1 \%$ had severe (stage III) COPD. Of the 48 participants identified as having COPD, only 7 (14.6\%) had been previously diagnosed with chronic bronchitis by a physician, and only $1(2.1 \%)$ with
COPD, i.e. 40 (83.3\%) of the patients with COPD had not been previously diagnosed.

All 216 (66.5\%) participants with scores $\leq 18$ but who had a normal result for spirometry are considered at risk of developing COPD according to the GOLD classification (3). The mean score was 13.9 (SD 3.6); all participants diagnosed with COPD in our study scored between 7 and 15 .

The prevalence of COPD is significantly higher with older age $(P<0.01)$; the highest prevalence was reported in the age group $\geq 65$ years $(31.2 \%)$ (Table 1). There was almost equal distribution between males (15.0\%) and females (15.7) $(P=0.897)$. (Table 1). Education level was not a statistically significant factor for COPD in our participants $(P=0.134)$.

The prevalence of COPD was greater among unemployed participants (44.2\%). Only 5.3\% of government employees had COPD $(P<0.01)$. It was also significantly more prevalent among those living where the crowding index was $>2(19.5 \%)(P=0.041)$.

Similarly, COPD prevalence was greater among those who had other chronic diseases $(20.7 \%)$ than those without $(10.4 \%)(P=0.011)$ (Table 2).

Prevalence of COPD was significantly higher with increasing pack years smoking. The prevalence was $21.4 \%$ among those with $>40$ pack years followed by $19.4 \%$ among those with 21-40 pack years and only $3.9 \%$ among

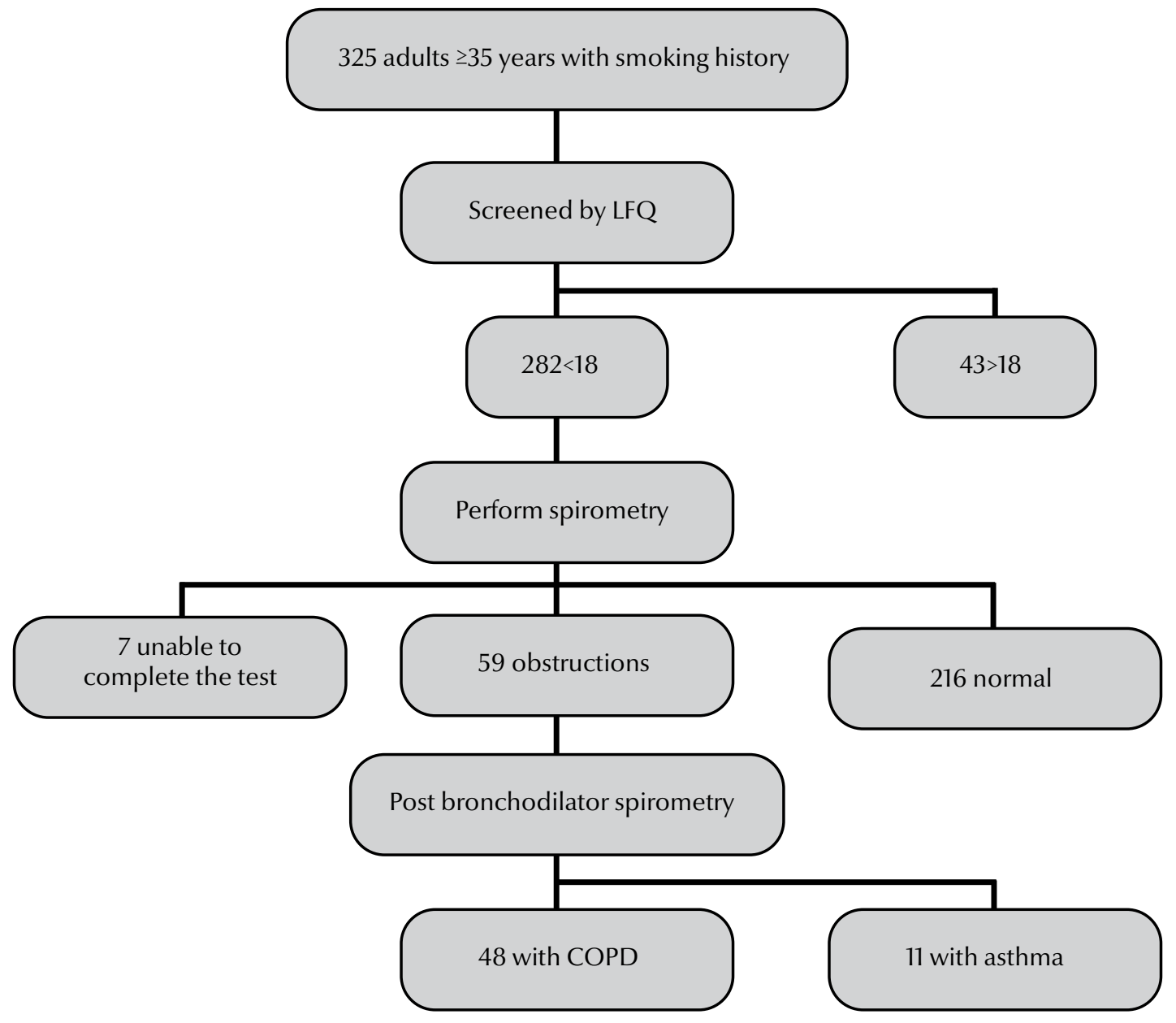

Figure 1. Schema showing classification of the study sample throughout the study and final assessment 


\begin{tabular}{|c|c|c|c|c|c|c|}
\hline \multirow[t]{2}{*}{ Factor } & \multicolumn{2}{|c|}{ With COPD $(n=48)$} & \multicolumn{2}{|c|}{ Without COPD $(n=270)$} & \multirow[t]{2}{*}{$\chi^{2}$} & \multirow[t]{2}{*}{$P$-value } \\
\hline & No & $\%$ & No & $\%$ & & \\
\hline \multicolumn{7}{|l|}{ Chronic disease } \\
\hline Present & 30 & 20.7 & 115 & 79.3 & \multirow{2}{*}{6.5} & \multirow{2}{*}{0.011} \\
\hline Absent & 18 & 10.4 & 155 & 89.6 & & \\
\hline \multicolumn{7}{|l|}{ BMI } \\
\hline Below normal/normal & 14 & 16.9 & 69 & 83.1 & \multirow{3}{*}{0.705} & \multirow{3}{*}{0.703} \\
\hline Overweight & 18 & 16.1 & 94 & 83.9 & & \\
\hline Obese & 16 & 13.0 & 107 & 87.0 & & \\
\hline \multicolumn{7}{|l|}{ Pack years smoking } \\
\hline$\leq 20$ & 4 & 3.9 & 99 & 96.1 & \multirow{3}{*}{15.1} & \multirow{3}{*}{0.001} \\
\hline $21-40$ & 19 & 19.4 & 79 & 80.6 & & \\
\hline$>40$ & 25 & 21.4 & 92 & 78.6 & & \\
\hline
\end{tabular}

those with $\leq 20$ pack years $(P=0.001)$ (Table 2).

Logistic regression was used to identify the independent, unconfounded, risk factors of COPD (as the outcome variable). Two explanatory variables had a statistically significant association with COPD risk: pack years smoking, highest pack year $(>40)$ (OR $=5.37$; $95 \%$ CI: $1.70-16.91, P=0.004)$ and pack year $21-40(\mathrm{OR}=5.15 ; 95 \%$ CI: $1.62-16.29, P=0.005)$, and older age $(\geq 55$ years $)(\mathrm{OR}=2.14,95 \% \mathrm{CI}$ : 1.04-4.39, $P=0.038$ ) (Table 3).

The remainingvariables (sex, marital status, education level, crowding index, body mass index, presence of chronic disease) had no statistically significant association with the outcome.

\section{Discussion}

The prevalence of COPD has been widely reported from several countries mainly the developed countries. There is a wide variation in the prevalence reported from different countries due to differences in methodology, diagnostic criteria and type and age of population included.

In the current study on adult smokers aged $\geq$ years, the risk of getting COPD was $86.8 \%$, and the prevalence of COPD was $15.1 \%$. This is similar to the prevalence reported in studies from Sweden (14\%), Spain (15\%), the United States of America (USA) (14.2\%), Germany (13.2\%) and Turkey (18.1\%) (14-18). It is higher than the prevalence reported in the BREATHE study, which was conducted in Egypt (3.5\%),

\begin{tabular}{|c|c|c|c|}
\hline Factor $^{\mathrm{a}}$ & Odds ratio & 95\% confidence interval & $P$-value \\
\hline Pack years smoking & & & 0.012 \\
\hline$>40$ versus $<20$ & 5.371 & $1.70-16.91$ & 0.004 \\
\hline $21-40$ versus $<20$ & 5.150 & $1.62-16.29$ & 0.005 \\
\hline Age (years) & & & 0.038 \\
\hline 55 versus $<55$ & 2.140 & $1.04-4.39$ & $0.038^{`}$ \\
\hline
\end{tabular}

$P($ model $)<0.001$.

Overall predictive accuracy $=84.9 \%$.

${ }^{a}$ The following variables were also included in the model: sex, marital status, education level, crowding index, income, body mass index, presence of comorbid chronic diseases.

Jordan (5.4\%), Lebanon (5.3\%), Syria (6.1\%) and the United Arab Emirates $(1.9 \%)(8)$. The difference in prevalence is because this large study included the general population, i.e. smokers and non-smokers, which accounts for the lower prevalence.

More than two-thirds of COPD cases in the current study were moderate stage; more than a quarter had severe and only $10 \%$ had the mild type. Similar findings were found in Lebanon with $58.3 \%$ of COPD patients having moderate disease, $20.3 \%$ severe disease and $17.6 \%$ mild disease (19).

In other countries, such as Sweden, the USA, Japan and Korea, most COPD cases were mild (stage I) followed by moderate and severe stages $(14,16,20,21)$. This difference could be attributed to including the general population or the early detection of cases due to better health care in these developed countries. This is supported by the finding that more than $83 \%$ of the cases were diagnosed as having COPD for the first time during our study. This is supported by the findings of some other studies $(19,22)$. There are 2 possible explanations for the low number of diagnoses of COPD. One is the reluctance of smokers to consult for symptoms they consider normal, such as cough or expectoration. Such patients usually seek medical help only 
when they experience dyspnoea and exacerbations at a relatively advanced stage of the disease. The second is the low use of pulmonary function tests by physicians.

Our study showed that older age and increased pack years smoking are the main factors associated with COPD development. Approximately 1 in $10 \mathrm{pa}-$ tients aged $<55$ years and 1 in 4 patients aged 55 years or older had COPD, and
$22.4 \%$ of those with pack years smoking $>30$ develop COPD compared with $7.2 \%$ of those with pack years $\leq 30$, This is comparable to the findings of other studies (19,22-24). Chronic inhaled cigarette smoke leads to chronic lung inflammatory response, which induces parenchymal tissue destruction and disrupts the normal repair mechanism leading to airway fibrosis and narrowing and a decrease in FEV1 (3).
As this was a cross sectional study any causal relationship cannot be inferred. Also we used a convenience sample (non-probability) which comprised attendees of primary health care centres. This could limit the generalizability of the study results.

\section{Funding: None.}

Competing interests: None declared.

\section{References}

1. Report on the global tobacco epidemic. Geneva: World Health Organization; 2011.

2. Lopez AD, Shibuya K, Rao C, Mathers CD, Hansell AL, Held LS, et al. Chronic obstructive pulmonary disease: current burden and future projections. Eur Respir J. 2006;27:397-412. PMID:16452599

3. (GOLD). Global strategy for the diagnosis, management and prevention of COPD - 2016. Global Initiative for Chronic Obstructive Lung Disease; 2016 (http://goldcopd.org/global-strategy-diagnosis-management-prevention-copd-2016/ http://www.goldcopd.org/, accessed 2 March 2017).

4. Van Schayck CP, Chavannes NH. Detection of asthma and chronic obstructive pulmonary disease in primary care. Eur Respir J. 2003;21(Suppl.39):16s-22s. PMID:12572697

5. Marsh S, Aldington S, Shirtcliffe P, Weatherall M and Beasley R. Smoking and COPD: what really are the risks? Eur Respir J. 2006;28:883-4. PMID:17012635

6. Boggia B, Farinaro E, Grieco L, Lucariello A, Carbone U. Burden of smoking and occupational exposure on etiology of chronic obstructive pulmonary disease in workers of southern Italy. J Occup Environ Med. 2008;50(3):366-70. PMID:18332787

7. Halpin DM, Miravitlles M. Chronic obstructive pulmonary disease: the disease and its burden to society. Proc Am Thorac Soc. 2006;3(7):619-23. PMID:16963544

8. Tageldin MA1, Nafti S, Khan JA, Nejjari C, Beji M, Mahboub B, et al. Distribution of COPD-related symptoms in the Middle East and North Africa: result of BREATHE study. Respir Med. 2012;106(Suppl.2):s25-32. PMID:23290701

9. Hasselgren $M$, Arne $M$, Lindahl A, Janson S, Lundback B. Estimated prevalences of respiratory symptoms, asthma and chronic obstructive pulmonary disease related to detection rate in primary health care. Scand J Prim Health Care. 2001;19(1):54-7. PMID:11303549

10. Lundback B, Lindberg A, Lindstrom $M$, Ronmark E, Jonsson AC, Jonsson $\mathrm{E}$, et al. Not 15 but $50 \%$ of smokers develop COPD?Report from the Obstructive Lung Disease in Northern Sweden studies. Respir Med 2003;97(2):115-22. PMID:12587960

11. Stratelis G, Jakobsson P, Molstad S, Zetterstrom O. Early detection of COPD in primary care: screening by invitation of smokers aged 40 to 55 years. Br J Gen Pract. 2004;54(500):201-6. PMID:15006126

12. Yawn BP, Mapel DW, Mannino DM, Martinez FJ, Donohue JF, Hanania NA, et al. Development of the Lung Function Questionnaire (LFQ) to identify airflow obstruction. Int J Chron Obstruct Pulmon Dis. 2010;5:1-10. PMID:20368906

13. Miller MR, Hankinson J, Brusasco V, Brugos F, Cassaburi R, Coates A, et al. ATS/ERS TASK FORCE. Standardization of lung function testing. Eur Respir J. 2005;26:319-38.
14. Lindberg A, Bjerg A, Ronmark E, Larsson LG, Lundback B. Prevalence and underdiagnosis of COPD by disease severity and the attributable fraction of smoking: report from the Obstructive Lung Disease in Northern Sweden Studies. Respir Med 2006, 100(2):264-72. PMID:15975774

15. Peña VS, Miravitles $M$, Gabriel R, Jimenez-Ruiz CA, Villasante C, Masa JF, et al. Geographic variations in prevalence and underdiagnosis of COPD. Chest. 2000;118(4):981-9. PMID:11035667

16. Mannino DM, Homa DM, Akinbami LJ, Ford ES, Redd SC. Chronic obstructive pulmonary disease surveillance-United States, 1971-2000. MMWR Surveill Summ. 2002;51:1-16. PMID:12198919

17. Geldmacher $\mathrm{H}$, Biller $\mathrm{H}$, Herbst $\mathrm{A}$, Urbanski $\mathrm{K}$, Allison $\mathrm{M}$, Buist AS, et al. [The prevalence of chronic obstructive pulmonary disease in Germany, result of BOLD study.] Dtsch Med Wochenschr. 2008 Dec;133(50):2609-14 [in German]. PMID 19052996.

18. Gunen H, Savas S, Agil H, Yetkin O, Gulbas G, Mutlu LC, et al. Prevalence of COPD, first epidemiological study of a large region in Turkey. Eur J Int Med. 2008;19(7):499-504. PMID:19013377

19. Salameh $\mathrm{P}$, Waked $\mathrm{M}$. Chronic obstructive pulmonary disease and risk factors in Middle East countries; facts from Lebanon. Beirut: Lebanese University; (www.ul.edu.lb/files/announcements/annonce_16_2149_2641.pdf, accessed 14 February 2017).

20. Fukuchi $Y$, Nishimura $M$, Ichinose $M$, Adachi $M$, Nagai A, Kuriyama T, et al. COPD in Japan: the Nippon COPD Epidemiology study. Respirology. 2004;9(4):458-65. PMID:15612956

21. Yoo KH, Kim YS, Sheen SS, Park JH, Hwang Yl, Kim SH, et al. Prevalence of chronic obstructive pulmonary disease in Korea: the fourth Korean National Health and Nutrition Examination Survey, 2008. Respirology, 2011;16(4):659-65. PMID:21342331

22. Díaz J, de Castro Mesa C, Gontán García-Salamanca MJ, Lopez de Castro F. [Prevalence of chronic obstructive pulmonary disease and risk factors in smokers and ex-smokers.] Arch Bronconeumol. 2003;39(12):554-8 [in Spanish]. PMID:14636492

23. Mintz ML, Yawn BP, Mannino DM, Donohue JF, Hanania NA, Grellet CA, et al. Prevalence of airway obstruction assessed by lung function questionnaire. Mayo Clin Proc. 2011;86(5):37581. PMID: 21531880

24. Sandelowsky H, Ställberg B, Nager B and Hasselström J. The prevalence of undiagnosed chronic obstructive pulmonary disease in a primary care population with respiratory tract infections - a case finding study. BMC Fam Pract. 2011;12:122. PMID:22047519 